\title{
Treatment of Verapamil Toxicity in Intact Dogs
}

Richard Gay, Stephen Algeo, Richard Lee, Marcey Olajos, Eugene Morkin, and Steven Goldman

Departments of Internal Medicine and Pharmacology, Veterans Administration Medical Center, and University of Arizona, Tucson, Arizona 85723

\begin{abstract}
The treatment of verapamil toxicity was examined in lightly sedated dogs. Verapamil, administered as a bolus $(0.72 \mathrm{mg} / \mathrm{kg})$ followed by a continuous infusion $(0.11 \mathrm{mg} / \mathrm{kg}$ per $\mathrm{min})$, decreased cardiac output $(\mathrm{CO})$ from $3.1 \pm 0.1$ to $1.7 \pm 0.1 \mathrm{liter} / \mathrm{min}$ $(P<0.001$ ), heart rate (HR) from $85 \pm 4$ to $57 \pm 3$ beats $/ \mathrm{min}(P$ $<0.001$ ), left ventricular derivative of pressure with respect to time (LV dP/dt) from $2,085 \pm 828$ to $783 \pm 78 \mathrm{~mm} \mathrm{Hg} / \mathrm{s}(P$ $<0.001$ ), mean aortic pressure (AO) from $77 \pm 4$ to $38 \pm 2 \mathrm{~mm}$ $\mathrm{Hg}(P<0.001)$ and stroke volume from $39 \pm 3$ to $28 \pm 2 \mathrm{ml} /$ beat $(P<0.01)$. In verapamil-toxic animals isoproterenol increased $\mathrm{HR}, \mathrm{CO}, \mathrm{LV} d P / d t$, and AO; calcium chloride increased $\mathrm{LV}$ $d P / d t$ and AO; norepinephrine, epinephrine, and dopamine increased CO, AO, and LV dP/dt, atropine increased HR, CO, and AO. Phenylephrine (13-55 $\mu \mathrm{g} / \mathrm{kg}$ per min) produced no changes except a small increase in AO while very high dose phenylephrine ( $300 \mu \mathrm{g} / \mathrm{kg}$ per min) increased $\mathrm{AO}, \mathrm{CO}$, and $\mathrm{LV}$ $d P / d t$. 4-Aminopyridine (4-AP) increased HR, CO, LV dP/dt, and $A O$. When administered prior to verapamil, 4-AP prevented the development of verapamil toxicity as shown by the signifcantly higher AO $(P<0.001)$, CO $(P<0.01)$, and LV dP/dt $(P<0.01)$ when 4-AP followed by verapamil was compared to verapamil alone. In conclusion, there does not appear to be a single specific therapy for verapamil toxicity, however it can be partially corrected by presently available pharmacologic therapy and 4-AP.
\end{abstract}

\section{Introduction}

Verapamil has been shown to be effective treatment for supraventricular tachyarrhythmias, angina, variant angina, cardiomyopathy, and hypertension. Despite its wide use, systematic evaluation of the therapy of the toxic effects of verapamil has not been previously reported. Hemodynamic collapse with bradyarrhythmias and heart block have been reported with intentional overdoses as well as with usual therapeutic doses of verapamil. There are case reports of successful treatment of these effects with intravenous calcium (1-4) and beta adrenergic agonists $(5,6)$. There are also conflicting reports of failure of calcium administration $(5,6)$ and sympathomimetic amines $(4,5)$ to reverse the toxic effects of verapamil.

Recently 4-aminopyridine (4-AP), ${ }^{1}$ an antagonist of nondepolarizing, neuromuscular blocking agents, has been suggested

Address reprint requests to Dr. Gay, Cardiology Section, Tucson VA Medical Center, Tucson, AZ 85723.

Received for publication 6 September 1985 and in revised form 9 January 1986.

1. Abbreviations used in this paper: 4-AP, 4-aminopyridine; LV, left ventricular; SP, systolic pressure.

The Journal of Clinical Investigation, Inc.

Volume 77, June 1986, 1805-1811 as treatment for verapamil toxicity (7). To systematically evaluate the effectiveness of different pharmacologic agents in the treatment of verapamil intoxication, lightly sedated dogs were given large doses of intravenous verapamil and then the responses to calcium, isoproterenol, atropine, dopamine, epinephrine, norepinephrine, phenylephrine, and 4-AP were measured. The dose of verapamil was chosen to insure that these animals were obviously toxic. Large doses of each pharmacologic intervention were chosen to insure that they met or exceeded the maximal recommended dosages for these agents in the treatment of hemodynamic collapse (8).

\section{Methods}

General procedures. The experiments were performed on mongrel dogs $(20-25 \mathrm{~kg})$. The animals were sedated with acepromazine $(0.5 \mathrm{mg} / \mathrm{kg})$ and anesthetized with $0.3 \%$ halothane and oxygen. A balloon-tipped, flow directed, thermodilution catheter (Edwards Laboratories, Santa Ana, CA) was placed in the pulmonary artery from the left external jugular vein. In five animals this catheter was a pacing catheter with electrodes positioned in the right ventricle. A $5 \mathrm{Fr}$. polyethylene catheter was placed in the descending aorta from the left femoral artery. A 6 Fr. polyethylene catheter was placed in the left ventricle (LV) from the right femoral artery. No local anesthesia was required to insert these catheters. These catheters were connected to Statham P23ID strain manometers (Gould, Inc., Oxnard, CA) positioned at the mid-chest level and referenced to atmospheric pressure.

In place of the LV catheter, five dogs had a high fidelity micromanometer (P7; Konigsberg Instruments, Inc., Pasadena, CA) placed in the LV 2 wk prior to the study using operative techniques previously described (9). These manometers are routinely calibrated prior to insertion and cross calibrated weekly, in vivo, with the arterial pressure. These five animals, after a 2-wk recovery from surgery, underwent catheter placement as described above except a left ventricular catheter was not placed. Catheter placement required $<20 \mathrm{~min}$ of anesthesia. After the placement of catheters, the dogs were allowed to recover from anesthesia for at least $20 \mathrm{~min}$, or until responsive to voice commands, then morphine sulfate $(0.2 \mathrm{mg} / \mathrm{kg})$ was given to maintain this level of sedation and analgesia.

Data were recorded on an oscillographic recorder (VR-6, Electronics for Medicine, Pleasantville, NY) and an FM tape recorder (3968A, Hewlett-Packard, Waltham, MA). Values for left ventricular derivative of pressure with respect to time (LV $d P / d t)$ were obtained from a differentiating circuit in the oscillographic recorder. Cardiac output was recorded in triplicate and mean values reported for each measurement. Total systemic resistance was calculated: Mean aortic pressure - right atrial pressure/cardiac output $\times 80$ dyne $\mathrm{s} \mathrm{cm}^{-5}$.

Experimental protocol. Baseline pressures, heart rate, and cardiac output were obtained before any intervention. In addition, in five dogs the right ventricular pacing electrodes were stimulated to capture the ventricle at rates up to 200 beats $/ \mathrm{min}$. Verapamil was administered intravenously as a bolus of $0.72 \mathrm{mg} / \mathrm{kg}$ followed by a continuous infusion of $0.11 \mathrm{mg} / \mathrm{kg}$ per min. This large dose was chosen to insure that the animals were toxic. Repeat measurements were made when obvious clinical toxicity was present, as evidenced by at least a $25-\mathrm{mm} \mathrm{Hg}$ fall in LV systolic pressure (SP), a 25-beat/min decrease in heart rate and a $40 \%$ decrease in cardiac output. This occurred within 20 min after the start of the infusion. In the dogs with right ventricular pacing electrodes repeat pacing was performed after toxicity developed. 
The verapamil infusion was maintained throughout the experiment. When the hemodynamic changes had remained stable for $10 \mathrm{~min}$ the following interventions were instituted: calcium chloride $(10 \mathrm{mg} / \mathrm{kg}$ i.v. $)$ as a bolus; isoproterenol $(0.7 \mu \mathrm{g} / \mathrm{kg}$ per min i.v. $)$ infused for $10 \mathrm{~min}$; atropine $(0.04 \mathrm{mg} / \mathrm{kg}$ i.v. $)$ as a bolus; epinephrine $(1.3 \mu \mathrm{g} / \mathrm{kg}$ per $\mathrm{min}$ i.v.) infused for $10 \mathrm{~min}$; norepinephrine $(1.3 \mu \mathrm{g} / \mathrm{kg}$ per $\mathrm{min}$ i.v. $)$ infused for $10 \mathrm{~min}$; dopamine $(26.5 \mu \mathrm{g} / \mathrm{kg}$ per min i.v.) infused for $10 \mathrm{~min}$; phenylephrine (13-55 $\mu \mathrm{g} / \mathrm{kg}$ per min and $300 \mu \mathrm{g} / \mathrm{kg}$ per min i.v.) infused for $10 \mathrm{~min}$; and $4-\mathrm{AP}(0.5 \mathrm{mg} / \mathrm{kg}$ i.v. $)$ as a bolus, twice, $5 \mathrm{~min}$ apart.

After each intervention verapamil toxicity redeveloped within 20 min. Once the animals were toxic again and stable hemodynamics had been present for $10 \mathrm{~min}$, repeat measurements were made. Each animal received only two interventions on any given day except when calcium chloride was given. The duration of action of calcium chloride is short (45-60 s), therefore, it was elected to proceed with two additional interventions on those days. The order of administration of interventions was random except that whenever atropine or 4-AP were given, the experiment was stopped for the day. An average experiment lasted 60-90 min. During the experiment, fluid necessary for the verapamil infusion, intravenous flush after drug administration, and cardiac output determinations were given in the form of $5 \%$ dextrose. A maximum of 150 $\mathrm{ml}$ was given in any one experiment and urine output was not measured.

To study the effects of 4-AP alone and to determine if treatment with 4-AP would prevent the development of verapamil toxicity, five dogs received the above dose of 4-AP and hemodynamic measurements were made for $30 \mathrm{~min}$. A third $0.5-\mathrm{mg} / \mathrm{kg}$ dose of $4-\mathrm{AP}$ was then given followed by the verapamil bolus and infusion at the dose as above. Hemodynamic parameters were then recorded every $10 \mathrm{~min}$ for $30 \mathrm{~min}$.

In a separate series of experiments $(n=6)$ after recording baseline hemodynamic data, a lower dose of verapamil was administered as a bolus $(90 \mu \mathrm{g} / \mathrm{kg}$, i.v.) followed by a constant infusion ( $14 \mu \mathrm{g} / \mathrm{kg}$ per min). Hemodynamic data were again recorded $20 \mathrm{~min}$ after the start of the infusion.

To determine if the sedation altered the response to interventions, on a separate day four dogs were sedated with acepromazine $(0.5 \mathrm{mg} /$ $\mathrm{kg}$ ) and morphine sulfate $(0.2 \mathrm{mg} / \mathrm{kg})$ and given the same doses of calcium, isoproterenol, and atropine while heart rate was monitored in the absence of verapamil. The reproducibility of the hemodynamic changes of verapamil toxicity induced by the verapamil bolus and infusion was evaluated by administering verapamil to six dogs on two different days.

Statistical analysis. Differences between control, verapamil toxicity, and intervention measurements were analyzed for statistical significance using Student's $t$ test for paired data. Each intervention value was com- pared to the immediate preceding verapamil toxicity value. Differences between the initial verapamil toxicity value and subsequent toxicity values were analyzed using analysis of variance. To examine the changes after phenylephrine, Dunnett's test for multiple comparisons with a control group was used after analysis of variance had demonstrated statistically significant changes. To compare the response to the various interventions analysis of variance was performed. To compare verapamil toxicity after 4-AP to verapamil toxicity in the absence of 4-AP Student's $t$ test for unpaired data was used. To compare the results of verapamil toxicity on day 1 to day 2 in the animals that received verapamil on more than $1 \mathrm{~d}$ Student's $t$ test for paired data was used. A $P$ value $<0.05$ was considered statistically significant. All results are expressed as mean \pm standard error of the mean.

\section{Results}

Effect of verapamil. Verapamil administration initially caused hypotension and a resultant sinus tachycardia (Fig. 1). This was transient, usually lasting less than $2 \mathrm{~min}$. Ultimately, verapamil caused a decrease in heart rate, LV SP, aortic pressure, and LV $d P / d t$ (Figs. 1 and 2). Slowing of the sinus rate coupled with high degree atrioventricular block, junctional escape rhythms, and accelerated idioventricular rhythms were all seen with verapamil toxicity. Four animals became severely bradycardic and hypotensive during the infusion. In each case, cardiac arrest and death occurred in spite of the immediate availability of direct current defibrillation and all pharmacologic therapies except 4AP. The average responses to verapamil in the remaining animals are shown in Table I. Heart rate, cardiac output, LV $d P / d t$, mean aortic pressure, and stroke volume decreased significantly after verapamil administration. Both cardiac output and aortic pressure decreased and total systemic resistance was unchanged with verapamil. The verapamil toxic values prior to each intervention were not different from the initial verapamil toxic responses in the entire group of animals. In the six dogs that received the verapamil bolus and infusion on separate days there were no significant differences in heart rate, cardiac output, mean aortic pressure or LV $d P / d t$ on the second day after verapamil compared with the first day after verapamil. In the six dogs given the lower dose of verapamil mean aortic pressure decreased $(P$

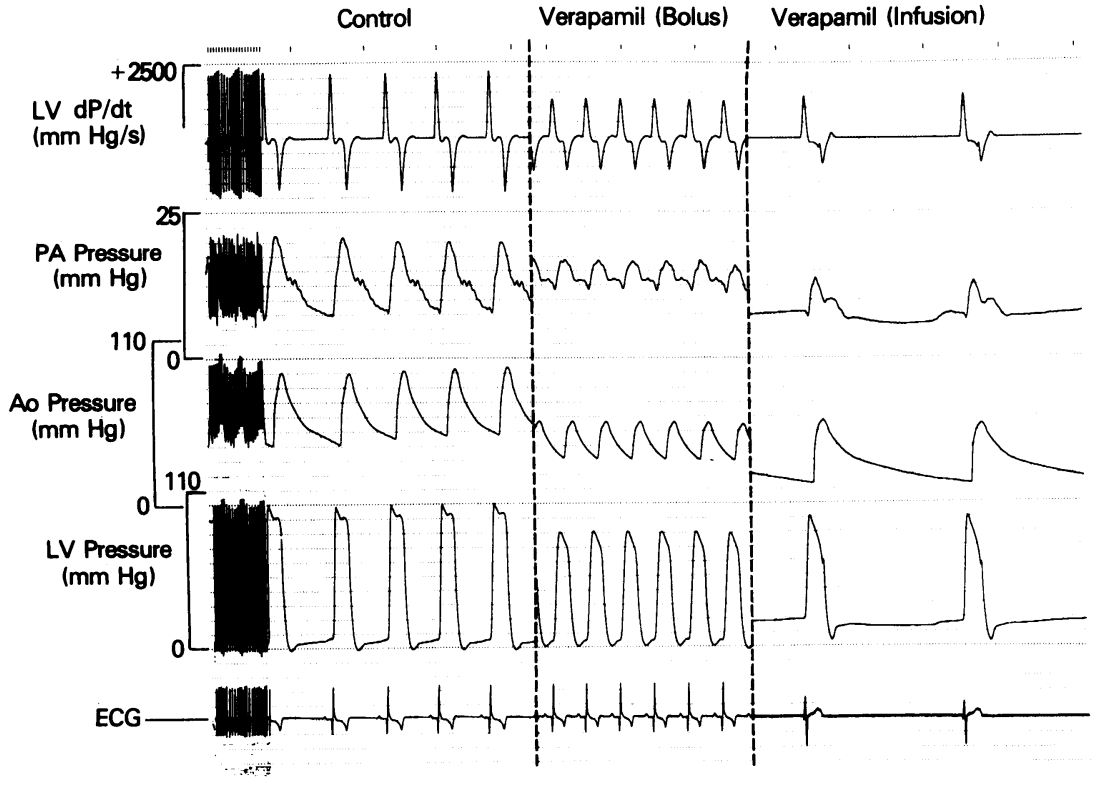

Figure 1 . The effects of verapamil $(0.72-\mathrm{mg} / \mathrm{kg}$ bolus followed by $0.11 \mathrm{mg} / \mathrm{kg}$ per min infusion) on ECG, LV pressure, $\mathrm{LV} d P / d t$, aortic (Ao) pressure, and PA pressure. Verapamil initially results in a sinus tachycardia, hypotension, and decrease in LV $d P / d t$. During the infusion a junctional escape rhythm is seen and the hypotension persists. Time lines at the top are $1 \mathrm{~s}$. 


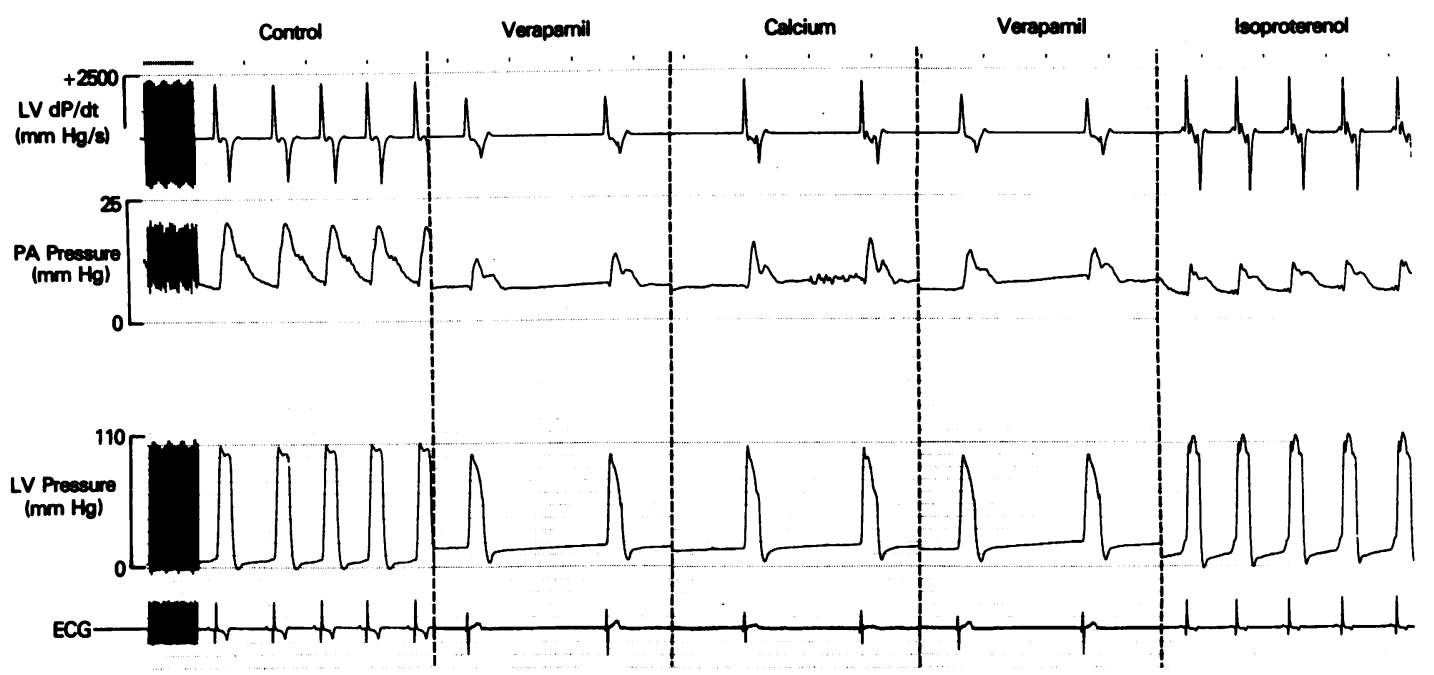

Figure 2. The effects of verapamil toxicity treated with calcium and isoproterenol. Verapamil decreases heart rate, LV pressure, and LV $d P / d t$. Calcium increases LV pressure and LV $d P / d t$. Isoproterenol increases heart rate, LV pressure, and LV $d P / d t$. Pulmonary artery (PA) pressure does not change. Time lines at the top are $1 \mathrm{~s}$.

$<0.02$ ) from $86 \pm 9$ to $65 \pm 5 \mathrm{~mm} \mathrm{Hg}$ and systemic vascular resistance decreased $(P<0.03)$ from $2,240 \pm 360$ to $1,581 \pm 199$ dyne $\mathrm{s} \mathrm{cm}^{-5}$. Heart rate, cardiac output, and LV $d P / d t$ were not changed.

Effect of calcium. After calcium administration there was no change in heart rate but aortic pressure, LV $d P / d t$, and LV SP increased (Fig. 2). The average responses to calcium in 10 animals are shown (Table II). There was no change in heart rate or cardiac output but there were significant increases in $\mathrm{LV} d P / d t(P$ $<0.05)$ and mean aortic pressure $(P<0.001)$.

Effect of atropine. The average responses to atropine in eight animals are shown (Table II). Atropine significantly increased $(P<0.05)$ heart rate, mean aortic pressure, and cardiac output but did not change LV $d P / d t$.

Effect of isoproterenol. After isoproterenol administration there was an increase in heart rate, aortic pressure, LV SP, and LV $d P / d t$ (Fig. 2). The average responses to isoproterenol in six animals are shown (Table II). There were significant increases in heart rate $(P<0.01)$, cardiac output $(P<0.05), \mathrm{LV} d P / d t(P$ $<0.01)$, and mean aortic pressure $(P<0.001)$.

Effect of norepinephrine. The average responses to norepinephrine in seven animals are shown (Table II). There were

Table I. Effects of Verapamil $(0.72 \mathrm{mg} / \mathrm{kg}$ Bolus Followed by $0.11 \mathrm{mg} / \mathrm{kg}$ per min Infusion) on Heart Rate and Hemodynamic Parameters in Lightly Sedated Dogs

\begin{tabular}{lcc}
\hline Toxicity & Control & Verapamil \\
\hline Heart rate, beats/min & $85 \pm 4$ & $57 \pm 3^{*}$ \\
Cardiac output, liters/min & $3.1 \pm 0.1$ & $1.7 \pm 0.1^{*}$ \\
$\mathrm{LV} d P / d t, \mathrm{~mm} \mathrm{Hg} / \mathrm{s}$ & $2,085 \pm 828$ & $783 \pm 78^{*}$ \\
Mean aortic pressure, $\mathrm{mm} \mathrm{Hg}$ & $77 \pm 4$ & $38 \pm 2^{*}$ \\
Stroke volume, $\mathrm{ml} /$ beat & $39 \pm 3$ & $28 \pm 2 \ddagger$ \\
Total systemic resistance, dyn $\mathrm{s} \mathrm{cm}^{-5}$ & $2,082 \pm 128$ & $1,901 \pm 146$
\end{tabular}

Values are mean \pm SEM for 23 dogs.

* $P<0.001$ vs. control.

$\ddagger P<0.01$ vs. control. significant increases in cardiac output $(P<0.05), \mathrm{LV} d P / d t(P$ $<0.01)$, and mean aortic pressure $(P<0.01)$ but heart rate did not change.

Effect of dopamine. The average responses to dopamine in seven animals are shown (Table II). There were significant increases in cardiac output $(P<0.01), \mathrm{LV} d P / d t(P<0.01)$, and mean aortic pressure $(P<0.05)$ but heart rate did not change.

Effect of epinephrine. The average responses to epinephrine in seven animals are shown (Table II). There was a significant increase in cardiac output $(P<0.05), \mathrm{LV} d P / d t(P<0.05)$, and mean aortic pressure $(P<0.05)$ but heart rate did not change.

Effect of phenylephrine. The average responses to the initial dose of phenylephrine in seven animals and to the very high dose of phenylephrine in five animals are shown (Table III). After phenylephrine (13-55 $\mu \mathrm{g} / \mathrm{kg}$ per min) administration there was a small but significant increase in mean aortic pressure but no change in $L V d P / d t$, CO or heart rate (Table III). Very high dose phenylephrine $(300 \mu \mathrm{g} / \mathrm{kg}$ per min) produced significant increases in LV $d P / d t(P<0.05)$, cardiac output $(P<0.05)$, and mean aortic pressure $(P<0.05)$ but heart rate did not change (Table III).

Effect of 4-AP. The average responses to 4-AP in seven animals are shown (Table IV). 4-AP resulted in significant improvements in heart rate $(P<0.02)$, mean aortic pressure $(P$ $<0.01)$, LV $d P / d t(P<0.01)$, and cardiac output $(P<0.01)$ in dogs during verapamil intoxication. Although all hemodynamic parameters were improved with 4-AP, there was no statistically significant difference in the response to 4-AP when compared with the other interventions evaluated for verapamil toxicity. 4AP, in the absence of verapamil, produced only a significant increase in $\mathrm{LV} d P / d t(P<0.05)$ from $1,455 \pm 128$ to $1,772 \pm 222$ $\mathrm{mm} \mathrm{Hg} / \mathrm{s}$. Heart rate, mean aortic pressure, and cardiac output were not significantly increased with 4-AP. In the dogs treated with 4-AP before the verapamil bolus and infusion, protection from the severe hemodynamic compromise of verapamil toxicity was shown by a significantly higher mean aortic pressure $(P$ $<0.001)$, cardiac output $(P<0.01)$, and LV $d P / d t(P<0.01)$ after verapamil compared with the values obtained after verapamil in the animals not treated with 4-AP (Table V). It should be noted that these values represent the response $30 \mathrm{~min}$ after 
Table II. Effects of Verapamil $(0.72 \mathrm{mg} / \mathrm{kg}$ Bolus Followed by $0.11 \mathrm{mg} / \mathrm{kg}$ per min Infusion) and

Then Calcium Chloride $(10 \mathrm{mg} / \mathrm{kg}, n=10)$, Atropine $(0.04 \mu \mathrm{g} / \mathrm{kg}, n=8)$, Isoproterenol $(0.7 \mu \mathrm{g} / \mathrm{kg}$

per min, $n=6)$, Norepinephrine (1.3 $\mu \mathrm{g} / \mathrm{kg}$ per min, $n=7)$, Dopamine (26.5 $\mu \mathrm{g} / \mathrm{kg}$ per min, $n=7)$, Epinephrine

$(1.3 \mu \mathrm{g} / \mathrm{kg}$ per min, $n=7)$ on Heart Rate and Hemodynamic Parameters in Lightly Sedated Dogs

\begin{tabular}{lllcl}
\hline & Heart rate & Cardiac output & LV $d P / d t$ & Mean aortic pressure \\
\hline & beats/min & liter/min & $m m ~ H g / s$ & $m m ~ H g$ \\
Toxicity & $51 \pm 4$ & $1.5 \pm 0.1$ & $896 \pm 198$ & $34 \pm 1$ \\
Calcium & $51 \pm 4$ & $1.9 \pm 0.2$ & $1,577 \pm 349^{*}$ & $42 \pm 1 \ddagger$ \\
Toxicity & $49 \pm 3$ & $1.6 \pm 0.1$ & $981 \pm 283$ & $36 \pm 1$ \\
Atropine & $62 \pm 6^{*}$ & $2.5 \pm 0.3^{*}$ & $803 \pm 211$ & $43 \pm 3^{*}$ \\
Toxicity & $49 \pm 5$ & $1.2 \pm 0.1$ & $1,017 \pm 296$ & $36 \pm 2$ \\
Isoproterenol & $78 \pm 9 \S$ & $3.1 \pm 0.6^{*}$ & $2,090 \pm 370 \S$ & $49 \pm 1 \ddagger$ \\
Toxicity & $66 \pm 2$ & $1.9 \pm 0.2$ & $665 \pm 34$ & $40 \pm 4$ \\
Norepinephrine & $79 \pm 10$ & $3.3 \pm 0.5^{*}$ & $1,754 \pm 246 \S$ & $63 \pm 2 \S$ \\
Toxicity & $57 \pm 3$ & $1.9 \pm 0.2$ & $847 \pm 159$ & $49 \pm 5$ \\
Dopamine & $68 \pm 8$ & $4.2 \pm 0.4 \S$ & $1,833 \pm 172 \S$ & $68 \pm 4^{*}$ \\
Toxicity & $55 \pm 5$ & $1.7 \pm 0.2$ & $1,125 \pm 317$ & $41 \pm 5$ \\
Epinephrine & $62 \pm 9$ & $2.6 \pm 0.4^{*}$ & $2,085 \pm 482^{*}$ & $54 \pm 7^{*}$
\end{tabular}

Values are mean \pm SEM. ${ }^{*} P<0.05$ vs. immediately preceding toxicity state. $¥ P<0.001$ vs. immediately preceding toxicity state. $\S P<0.01$ vs. immediately preceding toxicity state.

the last dose of 4-AP and during the verapamil infusion. After each of the other interventions, verapamil toxicity would redevelop within $20 \mathrm{~min}$ in the presence of the infusion of verapamil if the intervention was discontinued.

Ventricular pacing during verapamil toxicity. Five animals were paced at rates up to 200 beats/min from the right ventricular electrodes during both the baseline period and verapamil toxicity. In each animal there was complete ventricular capture at a rate to 200 beats/min in the presence of obvious verapamil toxicity.

Chronotropic responses in the presence and absence of verapamil. The chronotropic responses to calcium, isoproterenol, and atropine were measured in four sedated animals without verapamil. Prior to calcium, the heart rate was $81 \pm 14$ and after calcium, $89 \pm 14$ beats/min $(P>0.05)$. Isoproterenol increased the heart rate from $80 \pm 15$ to $147 \pm 3$ beats/min $(P<0.02)$ and atropine increased the heart rate from $95 \pm 14$ to $187 \pm 7$ beats/ $\min (P<0.01)$.

\section{Discussion}

Verapamil is a negative inotropic agent but with therapeutic doses in man and conscious animals this effect is usually offset by baroreceptor-mediated increases in inotropy and heart rate.
Verapamil also causes peripheral vasodilatation by its effect on vascular smooth muscle. Verapamil decreases sinus node discharge and conduction velocity through the atrioventricular node (10-12). In isolated Purkinje fibers, verapamil suppresses spontaneous and electrically stimulated rhythmic activity (13). In toxic doses, verapamil causes bradycardia with various degrees of atrioventricular block (Figs. 1 and 2). These effects are not mediated through the autonomic nervous system but are direct effects of verapamil on the conduction system (11). Verapamil intoxication produces severe hemodynamic deterioration in man and experimental animals due to its effects on both the heart and the peripheral circulation. With lower doses, the peripheral vasodilatory effects are most prominent and the systemic resistance decreases. With the toxic doses of verapamil even though the known vasodilator effects of verapamil result in hypotension, the negative inotropic effect causes a decrease in cardiac output resulting in a paradoxical return of systemic vascular resistance to near normal levels (Table I).

The effects of verapamil and other calcium channel blockers can be reversed in isolated physiologic systems such as papillary muscle preparations (14), perfused animal hearts $(10,15)$ pithed rats $(16)$, and open-chest dogs $(11,12)$. The treatment of the hemodynamic effects of toxic doses of verapamil with commonly

Table III. Effects of Verapamil $(0.72 \mathrm{mg} / \mathrm{kg}$ Bolus Followed by $0.11 \mathrm{mg} / \mathrm{kg} / \mathrm{min}$ Infusion) and Then Phenylephrine $(13-55 \mu \mathrm{g} / \mathrm{kg}$ per $\min , n=7)$ and $(300 \mu \mathrm{g} / \mathrm{kg}$ per min, $n=5)$ on Heart Rate and Hemodynamic Parameters in Lightly Sedated Dogs

\begin{tabular}{|c|c|c|c|c|}
\hline & Heart rate & Cardiac output & $\mathrm{LV} d P / d t$ & Mean aortic pressure \\
\hline & beats/min & liter/min & $m m ~ H g / s$ & $m m \mathbf{H g}$ \\
\hline Control & $96 \pm 9$ & $3.3 \pm 0.2$ & $1,708 \pm 163$ & $86 \pm 5$ \\
\hline Toxicity & $57 \pm 4^{*}$ & $1.9 \pm 0.2 \ddagger$ & $688 \pm 179^{*}$ & $36 \pm 2 \ddagger$ \\
\hline Phenylephrine $13-55 \mu \mathrm{g} / \mathrm{kg}$ per min & $56 \pm 3$ & $2.3 \pm 0.2$ & $1,036 \pm 288$ & $42 \pm 2 \S$ \\
\hline Phenylephrine $300 \mu \mathrm{g} / \mathrm{kg}$ per min & $62 \pm 2$ & $2.5 \pm 0.2 \S$ & $1,658 \pm 195 \S$ & $58 \pm 2 \S$ \\
\hline
\end{tabular}

Values are mean \pm SEM. $* P<0.05$ vs. control. $¥ P<0.001$ vs. control. $\S P<0.05$ vs. verapamil toxicity. 
Table IV. Effects of Verapamil $(0.72 \mathrm{mg} / \mathrm{kg}$ Bolus Followed by $0.11 \mathrm{mg} / \mathrm{kg}$ per min Infusion) and

Then 4-AP (1 mg/kg, $n=7)$ on Heart Rate and Hemodynamic Parameters in Lightly Sedated Dogs

\begin{tabular}{lclll}
\hline & Heart rate & Cardiac output & LV dP/dt & Mean aortic pressure \\
\hline & beats $/$ min & liter $/$ min & $\mathrm{mm} \mathrm{Hg} / \mathrm{s}$ & $\mathrm{mm} \mathrm{Hg}$ \\
Control & $103 \pm 9$ & $3.3 \pm 0.1$ & $2,092 \pm 200$ & $91 \pm 2$ \\
Toxicity & $61 \pm 3^{*}$ & $1.8 \pm 0.2 \ddagger$ & $1,010 \pm 170 \ddagger$ & $43 \pm 4 \ddagger$ \\
4-AP & $85 \pm 7 \S$ & $4.2 \pm 0.6^{\prime \prime}$ & $2,194 \pm 230^{\prime \prime}$ & $62 \pm 8^{\prime \prime}$
\end{tabular}

Values are mean \pm SEM. ${ }^{*} P<0.01$ vs. control. $\ddagger P<0.001$ vs. control. $\S P<0.02$ vs. verapamil toxicity. $" P<0.01$ vs. verapamil toxicity.

available agents has not been previously studied in intact animals. We found that verapamil intoxication can usually be partially reversed with common pharmacologic therapies at or above their maximal dosages. However, four dogs developed such severe hemodynamic deterioration with profound myocardial depression, severe bradycardia, and hypotension that they failed to respond to all forms of available therapy.

4-Aminopyridine is used as an antagonist of nondepolarizing neuromuscular blocking agents in Bulgaria (17). It increases inward calcium movement indirectly by blocking voltage-dependent potassium channels (18). There is also evidence that it may have a direct effect on voltage-dependent calcium channels (19). However, some investigators feel that 4-AP promotes the release of calcium from intracellular binding or storage sites or slows the binding of calcium to intracellar structures (20). In isolated trabecular muscle preparations, 4-AP has direct positive inotropic effects in addition to causing the release of endogenous catecholamines (20).

There are fatal cases of verapamil toxicity that failed to respond to conventional therapy (21). Recently, 4-AP has been shown to reverse verapamil intoxication in artificially ventilated cats (7). These results are consistent with the findings of the present study. However, in a study of spontaneously breathing rabbits, 4-AP did not prevent subsequent mortality caused by lethal doses of verapamil (22). In fact, the rabbits died with lower verapamil concentrations than rabbits that did not receive 4AP. In part because of the depressant effects of verapamil on neuromuscular function at high doses, it was postulated that the difference in response to 4-AP in these two studies could be due to the differences in ventilation of the animals or species differences (7). We evaluated the efficacy of 4-AP in the treatment of verapamil toxicity in lightly sedated, spontaneously breathing dogs. We also evaluated whether or not 4-AP would prevent the hemodynamic deterioration caused by a large dose of verapamil. The results show that 4-AP effectively reverses verapamil intoxication and that pretreatment with 4-AP protects the animal from the development of the deleterious hemodynamic effects of a large dose of verapamil. In the case of verapamil intoxication unresponsive to usual pharmacologic therapy 4-AP may prove to be effective.

The improvement in the myocardial depression during verapamil toxicity with isoproterenol is consistent with results obtained from papillary muscle preparations by Fleckenstein (14, 23 ) in which the negative inotropic effects of verapamil were reversed with isoproterenol. The other sympathomimetic agents with beta adrenergic activity also produced hemodynamic improvement. In the isolated rabbit heart, epinephrine has been shown to restore SA nodel automaticity in verapamil treated fibers (10). Conduction velocity of the AV node previously suppressed with verapamil has been partially restored with isoproterenol and epinephrine (11). In the present study, isoproterenol increased the heart rate to normal by increasing sinus rate and restoring atrioventricular conduction.

Intravenous bolus injections of calcium chloride improved the depression in inotropic state as evidenced by an increase in LV $d P / d t$. Similar improvements in inotropic state, independent of a change in heart rate, have been reported in open-chest dogs given calcium by an intravenous bolus infusion (12). However, calcium did not change the heart rate. These results are similar to work done in open-chest dogs where calcium failed to increase the conduction velocity previously suppressed with verapamil (11). Even though the duration of action of a bolus injection of intravenous calcium is short and it fails to reverse the electrophysiologic effects of verapamil, there are case reports of its efficacy in the treatment of verapamil intoxication in patients.

Atropine increased heart rate by restoring atrioventricular conduction when atrioventricular block was present and by increasing sinus rate. In addition, mean aortic pressure and cardiac output increased. In the appropriate clinical situation, when beta adrenergic agonists could have deleterious effects, atropine might be useful in the treatment of verapamil toxicity.

We examined the response to increasing doses of phenylephrine because of recent reports $(16,24-26)$ that verapamil blocked peripheral alpha adrenergic receptors. Phenylephrine,

Table V. Effects of 4-AP (1 mg/kg, $n=5)$ Given Prior to Verapamil ( $0.72 \mathrm{mg} / \mathrm{kg}$ Bolus Followed by $0.11 \mathrm{mg} / \mathrm{kg}$ per min Infusion) on Heart Rate and Hemodynamic Parameters in Lightly Sedated Dogs 30 min After the Start of the Verapamil Infusion

\begin{tabular}{|c|c|c|c|c|c|}
\hline & $n$ & Heart rate & Cardiac output & $\mathrm{LV} d P / d t$ & Mean aortic pressure \\
\hline & & beats/min & liter/min & $m m ~ H g / s$ & $\mathrm{~mm} \mathrm{Hg}$ \\
\hline Verapamil & 23 & $57 \pm 3$ & $1.7 \pm 0.1$ & $783 \pm 77$ & $38 \pm 2$ \\
\hline 4-AP + verapamil & 5 & $61 \pm 2$ & $2.5 \pm 0.3^{*}$ & $1,493 \pm 248^{*}$ & $67 \pm 6 \ddagger$ \\
\hline
\end{tabular}

Values are mean \pm SEM. ${ }^{*} P<0.01$ vs. verapamil. $\ddagger P<0.001$ vs. verapamil. 
a relatively specific alpha $a_{1}$ adrenergic agonist, in doses of 13-55 $\mu \mathrm{g} / \mathrm{kg}$ per min resulted in a small increase in mean aortic pressure. Much higher doses ( $300 \mu \mathrm{g} / \mathrm{kg}$ per min) produced significant increases in cardiac output, mean aortic pressure, and LV $d P$ / $d t$. The observed increase in cardiac output, mean aortic pressure, and $L V d P / d t$ with the administration of high dose phenylephrine is unexpected considering the alpha adrenergic activity of phenylephrine. Beta adrenergic-like effects of high dose phenylephrine have been proposed, however (27). In ganglionic blocked dogs, high dose phenylephrine increased heart rate and cardiac output (28). These increases were blocked with propranolol suggesting that at higher doses phenylephrine may have beta adrenergiclike effects. These beta adrenergic-like effects of high doses of phenylephrine could explain why phenylephrine, in the present study, increased cardiac output and $L V d P / d t$ in the verapamil toxic dogs. Another possibility is that since alpha adrenergic $_{1}$ agonists also increase venous return by effects on capacitance vessels $(28,29)$ this results in larger LV end diastolic volumes and stroke volumes accounting for the increase in cardiac output and LV $d P / d t$ noted.

Plasma verapamil concentrations were not measured in this study. A previous report in open-chest dogs showed that at infusion rates similar to those used in this study, the plasma levels of verapamil attained were in the range of 500 to $600 \mathrm{ng} / \mathrm{ml}$ (30). The dose of verapamil and plasma levels attained in the present study are different from the study of Wesseling et al. (22), in which the verapamil levels at death ranged from 8.8 to $13.7 \mathrm{mg} /$ liter. This could account for the lack of a protective effect of 4-AP in the earlier study (22). The dose of verapamil used in the present study was large and the fact that four animals progressively deteriorated to such an extent that cardiac arrest occurred, however, is further evidence that verapamil toxicity was present.

In this and previous studies $(30,31)$ it has been shown that verapamil causes marked depression of atrioventricular conduction. To assess whether the ventricular myocardium was still capable of responding to an electrical stimulus in the presence of verapamil toxicity ventricular pacing was attempted. Ventricular pacing to rates of 200 beats/min was performed successfully during verapamil toxicity. This suggests that in patients with verapamil intoxication and bradycardia unresponsive to pharmacologic therapy a ventricular pacemaker could be used to maintain heart rate.

In summary, verapamil toxicity results in hemodynamic collapse and occasionally death. In this study of the treatment of verapamil toxicity in dogs, we showed that commonly available pharmacologic agents are usually effective treatment. Atropine and calcium are partially effective and could be used when beta adrenergic stimulation might be deleterious. Ventricular pacing was shown to be possible and could be used to maintain heart rate. 4-AP was effective treatment and if available could be used for treatment of verapamil toxicity if other available agents failed.

\section{Acknowledgments}

We would like to acknowledge the clerical assistance of Ms. Mary Bryson, Ms. Ann Bruning, and the technical assistance of Ms. Gwen Roske.

This study was supported by grants from the Veterans Administration, the Gustavus and Louise Pfeiffer Research Foundation and National Institutes of Health (HL-20984).

\section{References}

1. DaSilva, O. A., R. A. DeMelo, and J. P. J. Filho. 1979. Verapamil acute self-poisoning. Clin. Toxicol. 14:361-367.

2. Perkins, C. M. 1978. Serious verapamil poisoning: treatment with intravenous calcium gluconate. Br. Med. J. 21:1127.

3. Moroni, E., P. F. Mannaioni, A. Dolara, and M. Ciaccheri. 1980. Calcium gluconate and hypertonic sodium chloride in a case of massive verapamil poisoning. Clin. Toxicol. 17:395-400.

4. Hattori, V. T., W. J. Mandel, and T. Peter. 1982. Calcium for myocardial depression from verapamil. (Letter.) N. Engl. J. Med. 306: 238.

5. Chimienti, M., M. Previtali, A. Medici, and M. Piccinini. 1982. Acute verapamil poisoning: Successful treatment with epinephrine. Clin. Cardiol. 5:219-222.

6. Crump, B. J., D. W. Holt, and J. A. Vale. 1982. Lack of response to intravenous calcium in severe verapamil poisoning. Lancet. ii:939940.

7. Agoston, S., E. Maestrone, E. J. van Hezik, J. M. Ket, M. C. Hourvertjeo, and D. R. A. Uges. 1984. Effective treatment of verapamil intoxication with 4-aminopyridine in the cat. J. Clin. Invest. 73:12911296.

8. Karliner, J., and G. Gregoratos, editors. 1981. Coronary Care. Churchill Livingstone, New York

9. Goldman, S., W. D. Hager, M. Olajos, M. Mayersohn, and D. Perrier. 1983. Effect of the ouabain-quinidine interaction on left ventricular and left atrial function in conscious dogs. Circulation. 67:10541058 .

10. Wit, A. L., and P. F. Cranefield. 1974. Effect of verapamil on the sinoatrial and atrioventricular nodes of the rabbit and the mechanism by which it arrests reentrant atrioventricular nodal tachycardia. Circ. Res. 35:413-425.

11. Zipes, D. P., and J. C. Fischer. 1974. Effects of agents which inhibit the slow channel on sinus node automaticity and atrioventricular conduction in the dog. Circ. Res. 34:184-192.

12. Hariman, R. J., L. M. Mangiardi, R. G. McAllister, Jr., B. Surawicz, R. Shabetai, and H. Kishida. 1979. Reversal of the cardiovascular effects of verapamil by calcium and sodium. Differences between electrophysiologic and hemodynamic responses. Circulation. 59:797-804.

13. Cranefield, P. F., R. S. Aronson, and A. L. Wit. 1974. Effect of verapamil on the normal action potential and on a calcium-dependent slow response of canine cardiac Purkinje fibers. Circ. Res. 34:204-213.

14. Fleckenstein, A. 1977. Specific pharmacology of calcium in myocardium cardiac pacemakers, and vascular smooth muscle. Annu. Rev. Pharmacol. Toxicol. 17:149-166.

15. Watanabe, A. M., H. R. Besch, Jr. 1974. Subcellular myocardial effects of verapamil and D600: Comparison with propranolol. J. Pharm. Exp. Ther. 191:241-251.

16. Cavero, I., N. Shepperson, F. Lefevre-Borg, and S. Z. Langer. 1983. Differential inhibition of vascular smooth muscle responses to $\alpha_{1}$ and $\alpha_{2}$ adrenoreceptor agonists by diltiazem and verapamil. Circ. Res. 52:I-69-76.

17. Bowman, W. C., and A. O. Savage. 1981. Pharmacological actions of aminopyridines and related compounds. Rev. Pure Appl. Pharmacol. Sci. 2:317-371.

18. Pelhate, M., and Y. Pichon. 1974. Selective inhibition of potassium current in the giant axon of the cockroach. J. Physiol. (Lond). 242: 90-91P.

19. Lundh, H., and S. Thesleff. 1977. The mode of action of 4aminopyridine and guanidine on transmitter release from motor nerve terminals. Eur. J. Pharmacol. 42:411-412.

20. Yanagisawa, T., and N. Toira. 1979. Positive inotropic effect of 4-aminopyridine on dog ventricular muscle. Naunyn. Schmiede. Arch. Pharmakol. Exp. Pathol. 307:207-212.

21. Van de Meer, J., and E. van der Wall. 1983. Fatal acute intoxication with verapamil. Neth. J. Med. 26:130-132.

22. Wesseling, H., M. C. Houwertjes, C. D. de Langen, and H. J. Kingma. 1983. Hemodynamic effects of high dosages of verapamil and 
the lack of protection by 4-aminopyridine in the rabbit. Arch. Int. Pharmacodyn. Ther. 266:106-112.

23. Fleckenstein, A. 1968. Experimental heart failure due to disturbances in high-energy phosphate metabolism. Proc. 5th. Eur. Congr. Cardiol. 5:255-269.

24. Van Meel, J. C. A., A. de Jonge, H. O. Kalhman, B. Wilffert, P. B. M. W. M. Timmermans, and P. A. Van Zweiten. 1981. Organic and inorganic calcium antagonists reduce vasoconstriction in vivo mediated by post synaptic alpha ${ }_{2}$-adrenoreceptors. Arch. Pharmacol. 316: 288-293.

25. Karliner, J. S., J. H. Motulsky, J. Dunlap, J. H. Brown, and P. A. Insel: Verapamil competitively inhibits alpha ${ }_{1}$-adrenergic and muscarinic, but not beta-adrenergic receptors in rat myocardium. $J$. Cardiovasc. Pharmacol. 4:515-520.

26. Motulsky, H. J., M. D. Snavely, R. J. Hughes, and P. A. Insel. 1983. Interaction of verapamil and other calcium channel blockers with alpha $_{1}$ - and alpha ${ }_{2}$-adrenergic receptors. Circ. Res. 52:226-231.
27. Govier, W. C. 1968. Myocardial alpha adrenergic receptors and their role in the production of a positive inotropic effect by sympathomimetic agents. J. Pharmacol. Exp. Ther. 159:82-90.

28. Appleton, C., M. Olajos, E. Morkin, and S. Goldman. 1985. Alpha- 1 adrenergic control of the venous circulation in intact dogs. $J$. Pharmacol. Exp. Ther. 233:729-734.

29. Zandberg, P., P. B. M. W. M. Timmermans, and P. A. van Zwieten. 1984. Hemodynamic profiles of methoxamine and B-HT 933 in spinalized ganglion-blocked dogs. J. Cardiovasc. Pharm. 6:256-262.

30. Mangiardi, L. M., R. J. Hariman, R. G. McAllister, Jr., V. Bhargava, B. Surawicz, and R. Shabetai. 1978. Electrophysiologic and hemodynamic effects of verapamil: Correlation with plasma drug concentrations. Circulation. 57:366-372.

31. McAllister, R. G. Jr., D. W. A. Bourne, and L. W. Dittert. 1977. The pharmacology of verapamil. I. Elimination kinetics in dogs and correlation of plasma levels with effect on the electrocardiogram. $J$. Pharmacol. Exp. Ther. 202:38-44. 